\title{
Notes on the Semantic Clash Caused by Individual Background, a Survey on Translation Materials in Qing Dynasty*
}

\author{
NING Yi-nuo, NIE Da-xin \\ Beijing Normal University, Beijing, China
}

\begin{abstract}
Influenced by translator's individual background, semantic clash is inevitable during the process of code-switching from source language to target language. This re-correspondence in semantic level has been well-shown not only in the translation of literature works, but in those of dictionary and glossary translations as well. Semantic clash, generally, is based on two main factors, one is the inherent difference between languages lying in typology features, the other is the social and culture diversity factors lying in the translator's personal background. According to actual translation works, social and culture factors of individual background take the dominant position unconsciously over other features in the process of code-switching. The present paper, branches the latter factor into certain categories, by analyzing bilingual dictionaries and glossaries cases in the $18^{\text {th }}$ century, Qing Dynasty, and indicates that the conceptual lagging, religion beliefs, living environment and political stand embedded in individual background will somehow result in semantic clash, which will lead the relevant research to pay more attention on cross-cultural literature translation.
\end{abstract}

Keywords: semantic clash, text translation, Qing Dynasty, Hua Yi Yi Yü

\section{Introduction}

In regard to the type of actual translation issue, semantic clash does not emerge more fundamental origins in nowadays, compared to the past as what people have imagined. Code-switching has been regarded as one of the core issues in translation since early times, and some former achievements were reached. Cicero (1949, p. 364), a translation theorist in early Western world, distinguished two translation methods in the year 46 B.C., i.e. "ut interpres", which means to translate was to render one word at a time, and "ut orator", which means to render source language text more freely into the target language in order to persuade a TL audience effectively. This method had not been challenged for centuries until Dryden (1680, pp. 68-72) proposed the three ways of cross-language translation in Preface to Ovid's Epistles,

First, that of Metaphrase, or turning an Authour word by word, and Line by Line, from one Language into another... The second way is that of Paraphrase, or Translation with Latitude, where the Authour is kept in view by the Translator, so as never to be lost, but his words are not so strictly follow'd as his sense, and that too is admitted to be amplified, but not alter'd... The Third way is that of Imitation, where the Translator (if now he has not lost that Name) assumes the liberty not only to vary from the words and sense, but to forsake them both as he sees occasion: and taking only some general

\footnotetext{
* Acknowledgements: The present paper is sponsored by The Specialized Research Fund for Young Teacher of BNU (No. 310400095).

NING Yi-nuo, M.A., Postgraduate, School of Chinese Language and Literature, Beijing Normal University.

NIE Da-xin, Ph.D., Lecturer, School of Chinese Language and Literature, Beijing Normal University.
} 
hints from the Original, to run division on the ground-work, as he pleases.

If we consider the theory above focused more on context form and meaning, the concept domesticating translation and foreignizing translation mentioned by Schleiermacher in 1813 gave a new perspective of cross-culture translation, representing "Leave the original author in peace, and move the reader to approach the author and Leave the reader in peace, but move the author to approach the reader" respectively.

All these achievements give us an idea and motivation to think about how translation process could be if we narrow the context, which means, compress context translation to word translation. As to the word to word translation materials including dictionaries and glossaries, semantic clash that purely caused by social and culture factors mainly can be divided into the following types: (1) Due to the semantic gap in conceptual or cultural difference in one language to another language, such as the meaning of “龙” (lóng) in Chinese on analogy to the surface-correspondence "dragon" in English. (2) Clash between extension meaning and root meaning during the code-switching of idiom. (3) Trans-boundary between semantic and pragmatic level affected by translator's virtual context. Such as, in certain circumstances, both "stomach" and "belly" could represent "stomach" in Chinese. This can be true that all these phenomena could not happen for no reason, but widely exist in the present literature and cross-language translations, which the social and culture factors of individual background take the dominant position unconsciously over other features in the process of code-switching.

Considering, as one of the important periods of cultural exchange and trade cooperation, a number of bilingual dictionaries and glossaries were compiled under the effort of local government, interpreters missionaries and businessmen in Qing Dynasty from $17^{\text {th }}$ to $19^{\text {th }}$ century, such as An English-Chinese Glossary and $A$ Portuguese-Chinese Glossary ${ }^{1}$, thus it is practical and meaningful to survey these documents and category to see what we could find in the hidden corner of cross-cultural translation.

What we need emphasize at first is, with a view to the complexity and flexibility among language, society, culture, religion, etc. all categories we are discussing in the following are made out of a "tendency causation", which means they are the main or more important key role than other factors, but not the only role that caused semantic clash.

\section{Semantic Clash Caused by Personal’s Conceptual Lagging}

It is known that through the evolution and development of Chinese language, one of the remarkable features is the transition from a language of monosyllabic-oriented to disyllabic-oriented. Therefore, when some concepts or usage of words newly emerged, people are not always being able to comprehend the updated semantic meaning of compounded disyllable word but still follow their instinct of former monosyllabic combination, even though the concept itself has already formed and used by certain community for a period of time.

As to two early bilingual dictionaries compiled in the $18^{\text {th }}$ century mentioned above, we found some items of this very type as following in Table 1 ,

\footnotetext{
${ }^{1}$ An English-Chinese Glossary and A Portuguese-Chinese Glossary are two officially authorized and published bilingual dictionary in Qianlong Period, $18^{\text {th }}$ century, which belonged to the series of Hua Yi Yi Yü. For the detail information of dictionaries and glossaries mentioned in this paper can be found in research of Nie and Wang (2015).
} 
Table 1

Semantic Clash of Conceptual Lagging

\begin{tabular}{ccc}
\hline Title of the dictionary & Chinese word & Foreign corresponding \\
\hline Ying Ji Li Guo Yi Yü & 中国 & middle country \\
(An English-Chinese Dictionary) & & \\
Bo Lü Du Ga Li Ya Hua & 京城 & muralha da corte \\
(A Portuguese-Chinese Dictionary) &
\end{tabular}

In the first example, the Chinese word 中国 (zhōng guó) corresponds by the interpreter through the combination meaning of each character, i.e. the former character to "middle" and the latter character to "country". Obviously, there does exist a suitable corresponding in English that is "China", which definitely existed at that period. Since it can be found in other items in the same dictionary that the word "China" was used to correspond Chinese word 汉 (hàn), it indicates that the interpreter should know the word "China". According to the Chinese transcription 煎乾的唎 (jiān gān dì li) of the same word, we reconstructed the English corresponding as "Qing Country" in our previous work. This semantic meaning had already formed in Song Dynasty mentioned by Shi Jie whose general idea can be concluded as "Middle Country in the name of the one who situated in the middle of world, for those who situated aside named foreign", and this "middle country" just is 中国. Besides, in Diccionario China-Portuguez (1833, p. 412) of the same period, the author used an expression of "no gramio da china" (lit. in the society of China) to describe the Chinese phrase 汉国怀 里 (hàn guó huái lĩ), in which the word "China" corresponds to 汉. All these facts show that at that moment, the new semantic meaning of 中国 as a compounded word appeared in government document was not widely accepted by those who living in the society, including Chinese people in southern coast and Foreign Missionaries.

The same situation happened in the second example. In nowadays understanding, the word 京城 (jīng chéng) refers to Beijing (or Peking), the Portuguese corresponding in the dictionary, however, refers to "wall of capital" and semantically translated word by word. If we go over the same dictionary, there is the Portuguese word "Corte" ("Capital" in English) to correspond its Chinese word 都 (dū). One of the interesting things is that in Ying Ji Li Guo Yi Yü, the item 京城 is also translated into Portuguese word "Corte", which seems that this concept of Chinese ran into a semantic clash because of the unawareness of the actual meaning. Even in bilingual dictionary Ying Hиа Zhu Jie (Chinese-English Dictionary with Annotation), compiled one century later in 1860, the word “London" has the Chinese corresponding as 英国京城 (yīng guó jīng chéng), literally means "Beijing in England", which demonstrates the word 京城 was recognized as the equivalent of "capital" from $18^{\text {th }}$ to $19^{\text {th }}$ century. According to previous study, the author of Bo Lü Du Ga Li Ya Hua is a missionary from Portugal who studied Chinese in southern coastal area of China and the Chinese he learnt was built up from the monosyllabic system. Since his living area at that time was far from the capital, even though the concept he acquired later in Beijing included the meaning of "Capital", the new semantic meaning of 京城, used by the imperial government in edicts and documents, did not update his knowledge which resulted in a conceptual lagging.

\section{Semantic Clash Caused by Personal's Religious Belief}

Due to the different religious belief between Western world and extreme-orient, in the process of translation, interpreters have a tendency on transplanting some foreign concepts into those who they are familiar with, instead of trying to make any explanation out of the original concept, especially under 
circumstances that without sufficient context, it resulted in a semantic clash. In early dictionaries, typical examples can be found as following:

Table 2

Semantic Clash of Religious Differences

\begin{tabular}{ccc}
\hline Title of the dictionary & Chinese word & Foreign corresponding \\
\hline Bo Lü Du Ga Li Ya Hua & 庙 & templo gentilico \\
(A Portuguese-Chinese Dictionary) & & Ying Ji Li Guo Yi Yü \\
(An English-Chinese Dictionary) & 经 & a prayed book \\
\hline
\end{tabular}

The first example, 庙 (miào) has its corresponding as "templo gentilico" in Portuguese. According to the common sense and the situation in Qing Dynasty around the $18^{\text {th }}$ century, this Chinese word refers to "Buddhist temple". The foreign corresponding, however, uses a word "gentilico" embodied with an extraordinary meaning, which purposely used to represent something with Christian. The semantic meaning of the original Chinese word, therefore, transferred into "temple of Christian", i.e. church in general. Yule (1913, p. 185) recorded a travelogue of an Italian named Odoricus came to China in early $14^{\text {th }}$ century (Yuan Dynasty). In his travelogue in Fuchow, a city in southern coast China, he noted "Multa sunt monasteria religiosorum idola colencium", which equals to "there are many religious monasteries". Obviously, judging on the social background of Yuan Dynasty, the building he mentioned must be "Buddhist temple". To someone who had never seen such a structure, could not know exactly what it is, but transplants some structure similar with. However, in our opinion, this might not be the same with the situation we are discussing. If we make a comparison with Ying Ji Li Guo Yi Yü, the word 庙 corresponds to "Church" as well. Considering what mentioned in Ao Men Ji Lüe $(1800)^{2}$, in order to make missionary work easier, churches in Macao area were named as various 庙 by imitating the Chinese tradition. This fact can just be represented the same situation in the above example that the interpreter, on the one hand, successfully achieved in propagandizing his religion, while effectively avoid causing trouble by the imperial government of China on the other hand.

It seems that in the process of translation, interpreters might extract their own experience and subjective judgment from source language, regardless of the real semantic meaning of the target language. Once move to the next example, we will get a clearer and more direct understanding of religious difference. In Table 2, Chinese word 经 (jīng) corresponds to "a prayed book". As we have mentioned earlier that all Chinese words, contained religious meaning in the dictionary are something related with Buddhism. That is to say, the original word 经 should refer to "sutra of Buddhist". The English corresponding, however, refers to prayer book in Western religion, bible, for instance. Furthermore, if compared with the same series of Hua Yi Yi Yü, ${ }^{3}$ the following corresponding are shown:

\footnotetext{
${ }^{2}$ Ao Men Ji Lüe (澳门纪略 in Chinese) published in 1800, is a local chronicles book of Macao, which considered to be the first book in China history about systematical introduction on Macao, includes history, geography, culture, customs, etc.

${ }^{3}$ Hua Yi Yi Yü (华夷译语) is a series of bilingual dictionary between Chinese and minority languages or Chinese and foreign languages, which authorized by the imperial government from Ming Dynasty to Qing Dynasty. Each dictionary follows a same compiling module that consists of Chinese word, non-Chinese corresponding and Chinese transcription.
} 
Table 3

Corresponding of Chinese Word 经 in Different Dictionaries

\begin{tabular}{ccc}
\hline Title of the dictionary & Chinese word & Foreign corresponding \\
\hline Bo Lü Du Ga Li Ya Hua & & escritura \\
(A Portuguese-Chinese Dictionary) & ق $\begin{array}{c}\text { Hui Hui Guan } Y \text { Y Yü } \\
\text { (A Chinese-Persian Dictionary) }\end{array}$ & \\
\hline
\end{tabular}

Here the same Chinese word 经 corresponds to totally different meanings according to different religious beliefs. The Portuguese word "escritura" means "bible or Christian book" in English, while the word means "The Koran" of Islam, through which give us a perfect proof that semantic clash can really be caused by personal religious belief.

\section{Semantic Clash Caused by Individual's Living Environment}

Compared to the first type of conceptual lagging, which focus more on the personal understanding of interior structure feature of disyllable word in Chinese language, the type we are going to discuss here, however, focus more on the living environment of individual interpreter in China. Also, it has no any relation with religion like what we mentioned above.

Table 4

Semantic Clash of Living Environment

\begin{tabular}{ccc}
\hline Title of the dictionary & Chinese word & Foreign corresponding \\
\hline $\begin{array}{c}B o \mathrm{Lü} \mathrm{Du} \text { Ga Li Ya Hua } \\
\text { (A Portuguese-Chinese Dictionary) }\end{array}$ & 冰 & caramelo \\
\hline
\end{tabular}

In the first example, the Chinese word 冰 (bīng) corresponds to "caramelo" in Portuguese (icing [n.] in English). To know about the semantic meaning, it is needed to certify the genre of the original Chinese word, since it has three genres as noun, verb and adjective respectively. Unfortunately, however, the bilingual dictionaries and glossaries in Ming and Qing Dynasties do not offer genre at all. On comparison with the word before and after in the same category ${ }^{4}$, which are 斗 (constellation) and 雨 (hail), it can be inferred that 冰 is a noun as well without any doubt, which means "ice". Due to the semantic corresponding, this Chinese word, in Portuguese, noted in Diccionario China-Portuguez (1833, p. 36) is "gelo" (ice in English). On contrast, the word "caramelo" in the table has two meanings in Portuguese shown in Diccionario Portuguez-China (1831, p. 134), one is "graupel", the other is "icing [n.]". Considering the geographical location of Beijing in any period in history, ice is a common natural phenomenon during winter and the imperial government used to store up ice even in summer time. It is clear that this solid form of water is quite different from graupel.

According to previous study, the Portuguese interpreter, before came to Beijing, lived in Macao, where the climate was far from getting snow or frozen icing. For them, real natural ice was rarely seen there. On the other hand, since Portuguese started to live in Macao in 1553, propagandizing and trading took the top place in Sino-Portuguese market, and in the $16^{\text {th }}$ and $17^{\text {th }}$ century Macao became the key position in the Maritime Silk Route connecting Asia and Europe. At that time, one of the important export goods from China was sugar, and

\footnotetext{
${ }^{4}$ In Ming and Qing Dynasties, bilingual dictionary and glossary like Hua Yi Yi Yü are compiled and grouped by words of the same class, ex. the class of color, the class of movement, the class of tools, etc.
} 
the totally amount was really considerable ${ }^{5}$. In addition, Glamann $(1958$, p. 153$)$, in the book Dutch-Asiatic trade, 1620-1740, mentioned "They [director of the Dutch East India Company] first of all ordered Chinese poeder, brood and kandij sugar".

Combining with the geographical condition and the semantic item "icing" of the word "caramelo", it can be inferred that, while in the process of translating, the Portuguese missionary miscomprehended the "ice" as "icing". Generally speaking, missionaries came to inland China from the southern coast at first, who should know the difference between "gelo" (ice) and "caramel" (icing). Due to the fact that, however, things he got in touch in daily communication and trading when he stayed in Macao were the semantic item "icing" of word "caramel", and this item gradually took the place of "ice". Thus, even the time when he came across the real translation in Beijing, the mode of thinking did not adjust to the present situation but still stayed at the former cognition and resulted in a confusing semantic clash.

\section{Semantic Clash Caused by Individual's Political Stand}

It is well-known in history that in Ming and Qing Dynasties, the imperial feudalist government, since considering China as the very core and Celestial Dynasty in the world and on protecting local agriculture and manufacture, periodically pressed ahead the Close-Door Policy to prevent the trade and multifaceted communication from Western country.

In the realm of texts translation, group of Chinese words, which are similar in fundamental semantic meaning but different in semantic degree and stylistic categories, correspond to the same foreign word. It is not because of the Chinese language competence of foreign missionaries, but because of political stand of certain person, for instance.

Table 5

Semantic Clash of Political Stand

\begin{tabular}{ccc}
\hline Title of the dictionary & Chinese word & Foreign corresponding \\
\hline Bo Lü Du Ga Li Ya Hua & 给 & dar \\
(A Portuguese-Chinese Dictionary) & 与 & \\
\hline
\end{tabular}

Apparently, the three Chinese word 给 (gěi), 与 (yǔ) and 赏赐 (shăng cì) correspond to the Portuguese word "dar" (give in English) without exception. Judging from the semantic and stylistics feature, this corresponding is impropriate in different ways. Firstly, in Chinese, the word 给 is more used in vernacular style, while the latter two words are more used in written style. Secondly, although share the similarity in stylistics, differences on semantic domain between word 与 and 赏赐 are clear to see, since 赏赐 contains more of a superior-subordinate relationship than the other. According to the explanation in Diccionario China-Portuguez (1833, p. 863), this 赏赐 corresponds to "premiar" (reward/award to subordinate in English), which means the reason why such situation happened was not a result of conceptual inconsistency or semantic gap between Chinese language and Portuguese language, but because of the political stand lying behind the word itself.

Based on the understanding of the Portuguese missionary, differences on semantic and stylistics among this group of words will not be an obstacle blocking the input of target language. Quite on the contrary, this

${ }^{5}$ Cf. Murakami, N. (1956). 長崎オランダ商館日記 (Nagasaki Oranda Shōkan Nikki). Tokyo: Iwanami Shoten. 1, p. 236. 
three-on-one corresponding will help him and others to understand the content of translated Chinese imperial documents and texts easier and more conveniently. In other words, whatever the original word is, 给, 与 or 赏赐, it will not make trouble and mistake if correspond to "dar" automatically.

In the $18^{\text {th }}$ century, as to the social status of "Christian Prohibition" in early Qianlong period and the "Chinese Rites Controversy" between Western missionaries and Chinese imperial government, it could be put on the stage that reflected behind such way of corresponding, is there any connection between religion protection and maintaining the relation among different countries. A further explanation is that, while translating the text of the emperor demands and imperial edicts by using the method shown in Table 5, the translation work will avoid causing dissatisfaction to the King of certain country and leading to a negative influential decision on bilateral relationship. For instance, the Macartney Embassy, who made the very first British diplomatic mission to china in late $18^{\text {th }}$ century, had a letter in reply to the King of England by Emperor Qianlong on title of Letter to George III, in September the year 1793. The first paragraph of the letter is:

奉天承运皇帝敕谕英吉利国王知悉, 咨尔国王远在重洋, 倾心向化, 特遣使恭类表章, 航海来廷, 吒祝万寿, 并备进方物, 用将忱㥵。

The King of England, of course, could not understand the meaning until foreign missionaries who served for Emperor Qianlong translate the full content, which was recorded as following:

You, O King, live beyond the confines of many seas, nevertheless, impelled by your humble desire to partake of the benefits of our civilization, you have dispatched a mission respectfully bearing your memorial. Your Envoy has crossed the seas and paid his respects at my Court on the anniversary of my birthday. To show your devotion, you have also sent offerings of your country's produce. (Backhouse \& Bland, 1914, p. 322)

It is not difficult to reach a finding on comparing these two texts that those words contained arrogant or imperial power of Celestial Dynasty in Chinese text are revised or deleted deliberately by translator. For example, the phrase 倾心向化 (qīng xīn xiàng huà) corresponds to a humble and modest saying of "impelled by your humble desire to partake of the benefits of our civilization". The original phrase, however, literally means "do yours utmost to come over and yield surrender to us". Also the phrase 吒祝万寿 (kòu zhù wàn shòu) corresponds to "pay respect on the birthday", yet the literal meaning is "kneel and kowtow to wish my longevity", which considered as a unacceptable insulting behavior by Western world. Semantically, although this translation does not correspond to the original meaning of Chinese text, it transfers into a better political stand for the one who belonged. At the same time, this method of translation could well explain the phenomenon why there are several-for-one corresponding in the dictionary we discussed above, in which those words contain bias, order of precedence, strong in emotional coloring are translated into semantically simple and vague word.

\section{Conclusion}

The aim of the present paper is to analyze and research the reason that caused semantic clash influenced by factors of translator. Through the discussion, it can be inferred that individual's person background will surely influence the actual translation direction and result. Even though the example and category are judged and drawn from word-to-word bilingual dictionaries, the fact, partially, can help the further research on literature work translation, since, for most of the time, regardless of those mother-tongue users, the translator himself is a second language user. What they have acquired and comprehended about society, culture, religion, 
and politics could reflect at the process of language output. These personal factors do not exist isolated, but shaped and appeared communal and universal. Although the material involved in the present paper is evidence in early time, the reference value and result, in certain realm, has its commonality and extensibility in today.

\section{References}

Backhouse, E., \& Bland, J. O. P. (1914). Annals and memoirs of the Court of Peking (From the $16^{\text {th }}$ to the $20^{\text {th }}$ century). Boston and New York: Houghton Mifflin Company.

Cicero, M. T. (1949). de Inventione, de Optimo Genere Oratorum, Topica (On invention. The best kind of orator. Topics). (H. M. Hubell, Ed. \& Trans.). Cambridge, MA: Harvard University Press.

Dryden, J. (1680). Preface to Ovid's epistles. London: Printed for Jacob Tonson.

Feng, X. Q. (1860). 英话注解 (Ying Hua Zhu Jie, Chinese-English dictionary with annotation). 守拙堂藏版 (Printed Verision by Qin Yang Shou Zhuo Tang).

Glamann, K. (1958). Dutch-Asiatic trade, 1620-1740. Copenhagen: Danish Science Press.

Gonçalves, J. A. (1831). Diccionario Portuguez-China (Dictionary Portuguese-Chinese). Macao: Real Collegio de S. Jose.

Gonçalves, J. A. (1833). Diccionario China-Portuguez (Dictionary Chinese-Portuguese). Macao: Real Collegio de S. Jose.

Murakami, N. (1956). 長崎オランダ商館日記 (Nagasaki Oranda Shōkan Nikki). Tokyo: Iwanami Shoten.

Nie, D. X., \& Wang, H. J. (2015). An introduction to An English-Chinese Dictionary and A Portuguese-Chinese Dictionary - Views on the language and society in Canton area from two unpublished official collative dictionaries compiled in the $18^{\text {th }}$ Century. Journal of Literature and Art Studies, 5(11), 1057-1069.

Schleiermacher, F. (2002). Ueber die verschiedenen Methoden des Uebersezens (On the different methods of translating). (R. Douglas, Trans.). On the different methods of translating. Western Translation Theory from Herodotus to Nietzsche, 225-238

Yin, G. R., \& Zhang, R. L. (1800) 澳门纪略 (Ao Men Ji Lüe, Local Chronicles of Macao, Local Chronicles of Macao). 江宁藩 署重刊本 (Reprinted Version by Jiangning Government Office).

Yule. H. (1913). Cathay and the way thither: Being a collection of medieval notices of China (Vol. II). London: Hakluyt Society. 